\title{
Unraveling the secrets recorded in the chemistry of bivalve shells
}

\author{
BERND R. SCHÖNE ${ }^{1 *}$,ELLEN SCHNABEL ${ }^{1}$, NILS HÖCHE $^{1}$, \\ NAOKO MURAKAMI-SUGIHARA ${ }^{2}$, KLAUS PETER \\ JOCHUM $^{3}$, KOZUE NiSHIDA $^{4}$, MELITA PEHARDA ${ }^{5}$, \\ KREŠIMIR MARKULIN ${ }^{5}$, HANA UVANOVIĆ ${ }^{5}$, KOTARO \\ SHIRAI $^{2}$ \\ ${ }^{1}$ Institute of Geosciences, University of Mainz, Germany \\ (*correspondence: schoeneb@uni-mainz.de) \\ ${ }^{2}$ Atmosphere and Ocean Research Institute, U. Tokyo, Japan \\ ${ }^{3}$ Max Planck Institute for Chemistry, Mainz, Germany \\ ${ }^{4}$ National Institute of Technology, Ibaraki College, Japan \\ ${ }^{5}$ Institute of Oceanography and Fisheries, Split, Croatia
}

Element chemical variations in bivalve shells remain puzzling to interpret and often do not seem to record environmental changes. Amongst others, the concentration of many cations is coupled to the prevailing shell microstructure and much higher near growth lines (primitive microstructures) than in microstructurally complex growth increments. To identify the underlying reasons and develop mathematical methods to eliminate vital effects from the element chemical data, we studied the link between the microstructure and chemistry in more detail. Results include: (1) In contrast to $\mathrm{Sr}, \mathrm{Mg}$ and $\mathrm{K}, \mathrm{Ba} / \mathrm{Ca}$ is uncoupled from the microstructure, but up to $2.5 \times$ higher in the hinge than the ventral margin of Arctica islandica. (2) Along isochronous transects from the myostracum toward the outer shell surface, $\mathrm{Si} / \mathrm{Ca}$ increased by $75 \%$, whereas $\mathrm{Na} / \mathrm{Ca}$ decreased by $7 \%$. Along this transect, the shell microstructure gradually changed from crossed-acicular to homogeneous. (3) In the hinge, all elements attained highest values along the axis of maximum growth. (4) The concentration of some elements ( $\mathrm{Sr}, \mathrm{B}$ etc.) varied significantly among specimens, others did not $(\mathrm{Ba}, \mathrm{Na})$. In conclusion, the calcifying front is chemically inhomogeneous, chemical differences among specimens relate to physiological differences, elements are differently affected by vital effects. Environmental information is recorded in elements, but superimposed by vital effects. 